\title{
Understanding Fall-Risk Factors for Inuvialuit Elders in Inuvik, Northwest Territories, Canada
}

\author{
Julia S. Frigault ${ }^{1,2}$ and Audrey R. Giles ${ }^{1}$
}

(Received 21 November 2017; accepted in revised form 15 August 2018)

\begin{abstract}
Older Indigenous adults in Canada experience disproportionately poorer health outcomes than older non-Indigenous adults. Current fall-prevention literature suggests that older Indigenous adults have higher rates of falls and fall-related injuries; however, no information exists on older Inuit adults' experience with falls. Using the social determinants of Inuit health $(\mathrm{SDoIH})$ as a conceptual framework, this research sought to understand which of the SDoIH are believed by stakeholders (i.e., local fall prevention programmers [LFPPs] and Inuvialuit Elders) to affect most the likelihood of older Inuvialuit adults' falls. The findings from the 12 semi-structured interviews and participant observations show that factors related to personal health status and conditions, personal health practices and coping skills, physical environments, social support networks, and access to health services increase older Inuvialuit adults' likelihood of experiencing a fall. Some determinants, however, decrease their likelihood of experiencing falls (health practices, coping skills, and access to health services), and others, such as culture, were perceived as having little influence on falls. Specific cultural practices were identified as factors that influence the likelihood of older Inuvialuit adults experiencing a fall; however, the overall Inuvialuit culture was not. In light of these findings, we offer recommendations for LFPPs in Inuvik to implement fall-prevention programs that adequately address the SDoIH influencing older Inuvialuit adults' fall risk and rates.
\end{abstract}

Key words: falls; injury; fall prevention; older adults; Indigenous; Inuit; Inuvialuit; social determinants of Inuit health; case study

RÉSUMÉ. Au Canada, les Autochtones âgés ont un état de santé excessivement moins bon que les non-Autochtones âgés. Selon la documentation actuelle sur la prévention des chutes, les Autochtones âgés ont des taux plus élevés de chutes et de blessures découlant de chutes. Cependant, il n'existe pas d'information au sujet des chutes chez les Inuits âgés. Cette recherche, ayant comme cadre conceptuel les déterminants sociaux de la santé des Inuits (DSSI), a cherché à comprendre les DSSI (comme les programmeurs locaux de prévention des chutes et les aînés inuvialuits) qui, selon les parties prenantes, sont les plus susceptibles d'avoir une incidence sur les chutes d'Inuvialuits âgés. D'après les constatations émanant des 12 entretiens semi-structurés et les observations des participants, les facteurs liés à l'état de santé et aux conditions personnelles, les pratiques personnelles en matière de santé, la capacité d'adaptation, le milieu physique, les réseaux de soutien social et l'accès aux services de santé ont une incidence sur les possibilités de chutes chez les Inuvialuits âgés. Cependant, certains déterminants diminuent leurs possibilités de chutes (les pratiques personnelles en matière de santé, la capacité d'adaptation et l'accès aux services de santé), tandis que d'autres facteurs, comme la culture, ont peu d'influence apparente sur les chutes. Certaines pratiques culturelles constituent des facteurs qui influencent les possibilités de chutes chez les Inuvialuits âgés, mais dans son ensemble, la culture inuvialuite n'est pas un facteur. À la lumière de ces constatations, nous présentons des recommandations aux programmeurs locaux de prévention des chutes d'Inuvik en vue de la mise en œuvre de programmes de prévention des chutes qui auraient une incidence réelle sur les DSSI influençant les risques et les taux de chutes chez les Inuvialuits âgés.

Mots clés : chutes; blessures; prévention des chutes; adultes âgés; Autochtone; Inuit; Inuvialuit; déterminants sociaux de la santé des Inuits; étude de cas

Traduit pour la revue Arctic par Nicole Giguère.

\footnotetext{
${ }^{1}$ School of Human Kinetics, University of Ottawa, 421 Montpetit, Ottawa, Ontario K1N 6N5, Canada

2 jfrig012@uottawa.ca

(c) The Arctic Institute of North America
} 


\section{INTRODUCTION}

Internationally, falls are considered a major public health concern (WHO, 2018). Approximately 646000 fatal falls occur each year, and falls are the second leading cause of unintentional injury death in all regions of the world (WHO, 2018). Individuals aged 60 and older are overrepresented among fall-related injuries and fatalities (Scott, 2012; WHO, 2018). The greater likelihood of older adults experiencing a fall and fall-related injury or fatality may be in part due to people living longer lives (the average life expectancy at birth of the global population is 72 years [WHO, 2016]), in combination with gradual agerelated changes and diseases, medications, lack of exercise, inappropriate footwear, or environments not adapted for aging populations (Scott, 2012; WHO, 2018).

Canadian older adults are no exception. According to the Public Health Agency of Canada (PHAC) "[f]alls remain the leading cause of injury-related hospitalizations among Canadian seniors, and between $20 \%$ and $30 \%$ of seniors fall each year" (PHAC, 2014:iii). Evidence also suggests that falls result in at least $95 \%$ of all hip fractures, resulting in death in approximately $20 \%$ of these cases (Ioannidis et al., 2009). PHAC (2014) has also indicated that older adults who experience a fall or fall-related injury can experience negative mental health outcomes, such as fear of falling, depression, immobilization, isolation, and loss of autonomy. Fall-prevention programs are needed in order to avoid the negative health outcomes associated with this type of injury among Canadian older adults.

The Canadian fall-prevention literature has shown that prevention programs and interventions can reduce falls among the elderly (Gillespie et al., 2012; Beauvais and Beauvais, 2014); however, not all groups of older adults are equally vulnerable to injury. Studies have shown that Indigenous peoples (First Nations, Métis, and Inuit) in Canada experience injuries that are intentional (interpersonal or self-inflicted, such as homicide, family conflict, violence, or assault) and unintentional (accidental, such as motor vehicle accidents, drowning, accidental poisoning, or accidental falls) at higher rates than nonIndigenous Canadians (Health Canada, 2002; Bjerregaard et al., 2004). Yet there continues to be little known about older Indigenous adults' rates of falls (Hill et al., 2014), and this is especially the case for older Inuit adults, for whom existing data provide only a generalized overview of injury rates, since there is limited information pertaining to fallrelated injuries among the Inuit (Bjerregaard et al., 2004).

In an attempt to address this gap in the research, we conducted research in Inuvik, Northwest Territories (NWT) $\left(68^{\circ} 21^{\prime} \mathrm{N}, 133^{\circ} 43^{\prime} \mathrm{W}\right)$, a community $1086 \mathrm{~km}$ northwest of Yellowknife and located on the Mackenzie River Delta (NWT Bureau of Statistics, 2016a). According to its most recent census, Inuvik has a population of 3170, of which 2059 individuals self-identify as Indigenous (NWT Bureau of Statistics, 2016b). The Indigenous populations in the community primarily consist of Inuvialuit (Inuit),
Gwich'in (First Nations), and Métis peoples. Although more recent statistical demographic profiles of these groups are unavailable, Statistics Canada (2007) cited these groups as representing $38.9 \%$ (Inuvialuit), 18.4\% (Gwich'in), and $4.7 \%$ (Métis) of Inuvik's population. The NWT Bureau of Statistics (2016b) also reported that Inuvik has an elderly population (individuals aged 60 and older) of 359 people (no breakdown by ethnicity is available). Older Indigenous adults and older non-Indigenous adults thus constitute approximately $11.3 \%$ of Inuvik residents (NWT Bureau of Statistics, 2016b).

Despite Inuvik's relatively small elderly population, the entire older adult demographic has experienced more falls and fall-related fatalities than younger demographics in the territory (NWT Health and Social Services, 2015). According to the NWT Health and Social Services (2015), from 2000 to 2009, fall-related death rates among those 60 to 69 years old were 6.5 times higher than the overall territorial rate. For people 70 and older, the rate was 17 times higher. Fall-related hospital admission rates among Inuit and Dene were also $31 \%$ and $38 \%$ higher than the territorial rate, and the highest number of fall-related injuries and deaths occurred within the regional centres of the Northwest Territories (Hay River, Fort Smith, and Inuvik) (NWT Health and Social Services, 2015). Moreover, the prevalence of falls and fall-related injuries or fatalities among older adults, specifically older Inuit adults in Canada, is expected to increase as a result of age-induced decline in physical, sensory, and cognitive function, as well as shifts in lifestyle and behaviour (e.g., medication use and physical activity levels) (Peel et al., 2002; Hill et al., 2014; Do et al., 2015).

Even with these data, there is still a notable gap in information about falls and fall-related injuries or fatalities among older Inuit adults in Canada. For example, older Inuvialuit adults' fall rates are missing from Northwest Territories fall-prevention findings, let alone Canadian research. Further, there is little to no information pertaining to the factors that influence the likelihood of older Inuvialuit adults experiencing a fall. This spurred us to conduct research with older Inuvialuit adults and local fallprevention programmers (LFPPs) in Inuvik. We worked in partnership with the participants in this study to respond to the following question: Which social determinants of Inuit health (SDoIH) do stakeholders (i.e., LFPPs and older Inuvialuit adults) believe most affect the likelihood of older Inuvialuit adults' falls?

We used the SDoIH (ITK, 2014) as a conceptual framework and conducted a thematic analysis (Braun and Clarke, 2006) of data from our 12 semi-structured interviews with LFPP and Inuvialuit Elders and participant observation notes. This analysis enabled us to identify (a) the SDoIH that participants believed increase the likelihood of falls (personal health status and conditions, personal health practices, and coping skills, physical environments, social support networks, and access to health services); (b) the SDoIH that participants believed decrease the likelihood 
of falls (health practices, coping skills, and access to health services); and (c) the SDoIH that were perceived as having little influence on falls (culture). The results from this study challenge current fall-prevention practices and indicate that fall-prevention researchers and practitioners should carefully consider specific determinants and their broader implications when developing fall-prevention programs and interventions for older Inuvialuit adults.

\section{LITERATURE REVIEW}

To examine the relationship between SDoIH and the likelihood of older Inuvialuit adults' falling, we situated our research within three areas of the literature: Indigenous health, the prevalence of fall-related injuries and fatalities among Indigenous peoples in Canada, and the SDoIH.

\section{Indigenous Peoples' Health}

In comparison to non-Indigenous populations, Indigenous populations experience tremendous physical health disparities and inequalities (Health Canada, 2012; Somogyi et al., 2015). For example, they experience higher rates of chronic diseases (e.g., diabetes, heart disease), infectious diseases (e.g., tuberculosis), physical inactivity, and mental health issues (e.g., suicide, drug abuse, and addiction) than non-Indigenous peoples (Health Canada, 2012; Somogyi et al., 2015). These differences are especially evident among the Inuvialuit population (Erber et al., 2010; Hopping et al., 2010; Owens et al., 2012). Past studies have indicated that approximately $30 \%$ of Inuvialuit people are at risk of developing one or more chronic health conditions (NWT Health and Social Sciences, 2005; ITK, 2008). Moreover, the Inuvialuit have among the highest rates of type 2 diabetes and cardiovascular disease in Canada's Arctic region (Owens et al., 2012).

Studies in these areas provide researchers with a better understanding of the health disparities and challenges older Inuvialuit adults face; however, information regarding their experiences of injury, specifically fallrelated injuries, is clearly lacking. There is also scant research on the direct and indirect influence of the SDoIH on the Inuvialuit's susceptibility to injury. Further, there is little recognition of the influence on Inuvialuit injury rates of the peripheral SDoIH, such as colonialism and culture. As a result, potential health disparities (e.g., in fall rates) affecting Inuit populations remain poorly understood (Somogyi et al., 2015).

\section{Indigenous Peoples and Falls}

Given the increasing global rate of fall-related injuries and fatalities among older adult populations (Hill et al., 2014; Naraynsingh et al., 2015; Stewart-Williams et al., 2015), it is not surprising that fall rates among older Canadian adults have been increasing as well. In recent years, researchers have found that almost half of older Canadian adults who fall are injured. Of these individuals, $5 \%$ to $25 \%$ sustain "serious injuries" (e.g., a fracture or sprain) (Herman et al., 2006). Moreover, falls have been found to account for at least $85 \%$ of all injuries that result in hospitalization in Canada among those aged 65 and older (Scott et al., 2010). Fall-prevention programs are needed not only to reduce older Canadian adults' likelihood of experiencing injury after a fall, but also to prevent falls altogether.

Although there has been a significant increase in literature on fall rates, fall-related injuries and fatalities, and fall prevention for older adults in Canada (Markle-Reid et al., 2015), little is known about the experiences of older Indigenous adults in Canada with regard to falling. Few firsthand accounts exist in the literature of older Indigenous adults' engagement with fall-prevention programs, and researchers and practitioners have failed to consistently document falls among older Indigenous adults, making it difficult to understand the nature and scope of falls among this population.

Some progress has been made in addressing this gap in research. Jin et al. (2015) studied the unintentional fallrelated injury incidence among Indigenous peoples in British Columbia, Canada, in comparison to the general population. They found that older Indigenous adults experience significantly higher rates of fall-related injuries and death than older non-Indigenous adults. In fact, unintentional falls among older Indigenous adults resulted in $20 \%$ of deaths and $46 \%$ of hospitalizations in this population. Additionally, Reading et al. (2011) conducted a fall-prevention study with a focus on older First Nations Elders in British Columbia, Canada, and found that fallrelated injuries and fatalities are anticipated to rise because of the expected growth of the older Indigenous adult population in Canada (Reading et al., 2011). They also reported that older Indigenous adults throughout Canada were twice as likely to be hospitalized as a result of falling than their non-Indigenous counterparts, which further highlights a specific need for Indigenous-focused fallprevention interventions and programs.

Even with the important insights provided by Jin et al. (2015) and Reading et al. (2011), key information concerning older Indigenous adults in Canada is missing. For Métis and Inuit populations in particular, published research on fall rates and preventative programs is nonexistent. Moreover, the factors that either directly or indirectly influence older Métis and Inuit adults' likelihood of experiencing a fall continue to be unknown.

\section{Social Determinants of Inuit Health}

According to the WHO (2017), the social determinants of health (SDH) are defined as "the conditions in which people are born, grow, live, work and age." These conditions include physical, mental, social, and contextual factors that may positively or negatively influence individuals' overall 
health and well-being (Davidson, 2014; WHO, 2017). Moreover, while the SDH have been articulated in many ways by various public health organizations, the PHAC (2011) identified the following as determinants of health for Canadians: income and social status; social support networks; education and literacy; employment and working conditions; social environments; physical environments; personal health practices and coping skills; healthy child development; biology and genetic endowment; health services; gender; and culture.

Current Canadian fall-prevention researchers have found that some determinants of health influence the likelihood that older adults will experience fall-related injuries. For example, several studies show that women are more likely to experience a fall or fall-related injury than men (Peel et al., 2002; Stevens and Sogolow, 2005; PHAC, 2014; Chang and Do, 2015). These findings are partly a result of women living longer than men, meaning that more people experiencing a fall are female and elderly (PHAC, 2014). Women are also more likely to have osteoporosis, and those with osteoporosis are predisposed to lose bone mass and density. Thus, females have greater fall risk and likelihood of injury (e.g., fracture) (Scott, 2012).

Researchers and practitioners therefore need to acknowledge the effect of determinants of health such as gender on people's well-being and quality of life - and in this case, the influence they have on the likelihood of older adults falling and injuring themselves - rather than focusing exclusively on individual biomedical factors (Davidson, 2014).

Few studies on the determinants of health are relevant to non-Euro-Canadian populations within Canada, such as Indigenous peoples or immigrants. While the SDH for non-Indigenous Canadians have been the focus of research since the early 1970s (Davidson, 2014), information pertaining to SDoIH emerged much later. Inuit Tapiriit Kanatami (ITK) (2014), in collaboration with the Inuit Public Health Task Group, outlined the determinants that have played and continue to play a significant role in Inuit health and well-being. The list includes quality of early childhood development, culture and language, livelihoods, income distribution, housing, personal safety and security, education, food security, availability of health services, mental wellness, and the environment. Importantly, these factors are "highly interconnected" (ITK, 2014:12) and differ from the determinants of health outlined by the PHAC (2011) (e.g., biology, genetic endowment, and gender are not identified as SDoIH).

In addition to establishing a list of determinants that were deemed relevant for assessing Inuit overall health and wellbeing, ITK (2014) reported that Inuit have lower incomes and fewer educational opportunities, live in impoverished communities and homes, experience extremely high rates of mental health issues, and have limited access to health services, in comparison to the average non-Indigenous Canadian.

Researchers need to be aware of the discrepancies Inuit experience regarding the determinants of health and, in the field of fall prevention, to look beyond individual biomedical factors to develop a better understanding of which determinants of health are the most relevant for older Inuit adults' falls. This is what we endeavoured to do through the research described below.

\section{EPISTEMOLOGY}

The authors, both Euro-Canadian females, used a constructionist epistemology throughout the research process, and we believe that this approach enabled us to better understand the factors that influence the likelihood of Inuvialuit Elders experiencing a fall. It also enabled us to co-identify (with participants) socio-cultural contexts that have formed LFPPs' and Inuvialuit Elders' understandings of falls, fall-related injuries or fatalities, and fall prevention.

\section{METHODS}

For this research, we conducted an exploratory case study (Yin, 1994) that utilized a participatory research approach (Maguire, 1987). A participatory approach to research is a "process of social investigation, education, and action" (Maguire, 1987:3) that enables researchers to co-identify (with community members) and address important issues, promote community participation and provide residents with a genuine voice in the research, and bridge gaps in knowledge and practice between researchers and communities (Maguire, 1987; Wallerstein and Duran, 2010). To apply these tenets to our research, the first author established a local advisory board that was composed of three stakeholders who live in Inuvik: Crystal McPhail, a Regional Occupational Therapist for the Inuvik Regional Hospital's Rehabilitation Department; Delores Harley, the Elders Coordinator for the town's local Friendship Centre, Ingamo Hall; and Shannon O'Hara, an Inuit Research Advisor for the Inuvialuit Regional Corporation (all names are used with permission). The advisory board members helped to ensure that our research and methods were the most appropriate for Inuvialuit Elders, helped recruit participants, and explained the inner workings of their community. The advisory board supported the use of an exploratory case study for this research. An exploratory case study permits researchers to study uncommon research topics in order to gain a better understanding of a specific case or similar cases (Yin, 1994). The first author, a Euro-Canadian graduate student, grew up in Beeton (a small town $73 \mathrm{~km}$ north of Toronto), Ontario, Canada, lived and conducted research in Inuvik from 16 September 2016 to 30 November 2016. The second author is of EuroCanadian heritage and has been conducting research in the Arctic and Sub-Arctic for almost 20 years. As a result of the authors' lack of lived experience in the region, the advisory committee played a key role in ensuring that Inuvialuit knowledge and ways of knowing, as well as regional health 
practices and policies, guided the research. Approval for this project was granted by the Research Ethics Board at the University of Ottawa and the Aurora Research Institute (which is responsible for issuing research licences for the NWT on behalf of the Government of the NWT).

Potential participants fell into two categories: Inuvialuit Elders and LFPPs. For Elder Inuvialuit participants, the inclusion criterion for participation was being at least 55 years old, the age at which researchers have considered Indigenous peoples in Canada to be older adults. The Inuit have a shortened life expectancy: the average Canadian man and woman are expected to live beyond 79 years and 83 years respectively, whereas Inuit male and female life expectancies are only 64 and 73 years (Wilson et al., 2010; Statistics Canada, 2015). Therefore, we followed other scholars, who have identified older Inuit adults as being 55 years of age and older (see Collings, 2001; Wilson et al., 2010). We also selected this age criterion because older adults are at a greater risk of falling than the rest of the population (Scott, 2012; Beauvais and Beauvais, 2014; Hill et al., 2014; Parachute, 2015; Stewart-Williams et al., 2015; Canadian Patient Safety Institute, 2017). The first author employed snowball sampling (Cohen and Arieli, 2011) to recruit eight older Inuvialuit adults (four males and four females, with ages ranging from 64 to 79 years), all of whom identified as Elders. To convey respect, throughout this paper, we refer to the older Inuvialuit adult participants as Inuvialuit Elders.

Judgement sampling was used to recruit LFPP participants (Marshall, 1996). According to Marshall (1996), judgement sampling occurs when researchers select participants based on specific criteria because it is believed these individuals will provide information that will answer the research questions. Thus, our specific criteria for inclusion were that LFPP participants be knowledgeable about and have training in fall prevention (e.g., Canadian Fall Prevention Curriculum). In addition, we specified that LFPP study participants had to have worked in fall prevention for at least one year to ensure that they were familiar with the area. The six LFPP participants included one man and five women; the man self-identified as Filipino-Canadian and the women self-identified as EuroCanadian. Two LFPP participants worked as occupational therapists; the other four were a long-term care worker, an older adult program coordinator, a rehabilitation assistant, and a community health representative.

The advisory board members agreed that participant observation (Dewalt and Dewalt, 2002) and semistructured interviews (Fontana and Frey, 2005) would be appropriate research methods. To that end, the first author volunteered with local older Indigenous adults at the Inuvik Regional Hospital's Elders' Day Program and at the local Friendship Centre (a non-profit community centre and Indigenous program/service delivery organization), Ingamo Hall. The Elders' Day Program provides daily (Monday to Friday, from 10 a.m. to 3 p.m.) activities and games for a select number of older adults in Inuvik; acceptance into the program depends on availability of space and the ability to cater to individuals' needs. Ingamo Hall offers all the town's residents a variety of educational, recreational, social, and multicultural activities and events, including Elders' luncheons, which the first author attended.

The first author volunteered with and observed elderly participants at the Elders' Day Program every Monday and Thursday for six weeks, and volunteered and observed at Ingamo Hall five times. Volunteering and observations were limited at Ingamo Hall to the days of its Elder luncheons, which occurred every other Thursday. Participant observation provided the opportunity to observe the services offered to older Indigenous adults in Inuvik. Observing Inuvialuit Elder participants' daily activities, interactions, and events led to greater familiarity with their culture and social world (Dewalt and Dewalt, 2002) and clearer insight into Inuvialuit Elders' understanding of falls and their prevention in these public settings.

The first author conducted semi-structured interviews to identify factors related to the SDoIH that participants believed to either increase or decrease the likelihood of an older Inuvialuit adult's falling. Semi-structured interviews are interviews guided by predetermined topics and openended questions that elicit discussions on the various influences in participants' everyday lives (Fontana and Frey, 2005). We agreed with the advisory board that this type of interview was most appropriate for our research because it offered participants more opportunities to develop, elaborate, and share their opinions (Fontana and Frey, 2005), and enabled the interviewer to prompt discussion, build rapport, and gather pertinent information in a respectful manner (Barriball and While, 1994; Ayres, 2008). The first author thus facilitated 12 semi-structured interviews (10 one-on-one interviews and two two-on-one interviews), with a total of 14 participants (six LFPPs and eight Inuvialuit Elders), and then digitally recorded and transcribed all interviews verbatim. Participants received interview transcripts by mail or email for feedback; however, only one participant edited the transcript. To recognize the expert contributions and knowledge of the Inuvialuit Elders (Giles and Castleden, 2008), the participants' names appear with permission.

\section{ANALYSIS}

To analyze the data set, we used Braun and Clarke's (2006) six-step thematic analysis framework. NVivo 11 software enabled us to organize the interview transcripts and observation notes. As stipulated by Braun and Clarke (2006), our first step was to familiarize ourselves with these and to record any ideas we had for potential themes to be used later in the analysis. Second, we identified initial codes within our data and then attached these codes to our transcripts and notes as a way to organize the data. During this process, we initially based our codes on ITK's (2014) list of SDoIH; however, we found this approach to be 
limiting. Of their suggested determinants, we were able to establish links only to livelihood, housing, the availability of health services, mental wellness, and the environment, which left a portion of our data untouched. We therefore decided to include codes that were also based on the PHAC's (2011) determinants of health, such as physical environments, access to health services, and culture. This approach enabled us to progress to the third phase of our analysis: sorting our codes into potential themes. Fourth, we reviewed and refined our themes to ensure that they suited the initial context of our research. The fifth step comprised two stages: the first author returned to Inuvik from 1 April 2017 to 9 April 2017 to review, name, and define the potential themes with the participants so that they reflected the broader themes within our data. For the final step, we established three themes: the SDoIH that participants believe increase likelihood of falls, decrease likelihood of falls, and have little influence on falls.

\section{RESULTS}

\section{SDoIHs That Increase Likelihood of Falls}

Personal Health Status and Conditions: Participants (four female LFPPs, one male Inuvialuit Elder, and two female Inuvialuit Elders) agreed that pre-existing and chronic health conditions increase the likelihood that an older Inuvialuit adult will experience a fall. The examples these participants provided related predominantly to physical health conditions (e.g., changes to physical function, vision and auditory changes, poor balance and stability, general weakness and frailty); however, cognitive health conditions were also identified as fall-risk contributors. One LFPP, Chelsey, elaborated on how cognitive illnesses and impairments can catalyze individuals' physical health conditions and ultimately increase Elders' likelihood of experiencing fall-related injuries:

\footnotetext{
Dementia, and any type of cognitive changes where there is impulsivity or lack of insight into some physical function, like into their own - or memory changes. So, if they have poor physical function, and...they can't remember that they have poor physical function... and then they'll get up and fall.
}

Personal Health Practices and Coping Skills: Of the many health practices and coping skills identified as factors increasing the likelihood that an older Inuvialuit adult will fall, the most commonly cited one (by one male LFPP, four female LFPPs, three male Inuvialuit Elders, and one female Inuvialuit Elder) was the use of improper footwear. LFPP participants indicated that traditional footwear (e.g., kamiks, mukluks) can increase the likelihood of a fall. As one LFPP, Crystal M, stated, "I think one is footwear... And it's usually like super worn down mukluks that are like glass, you know? Just because the moosehide [caribou, rabbit, muskrat, beaver, wolf, or seal skin] gets really slick." Chelsey (LFPP) also agreed and noted, "Their footwear sometimes [gets] slick-like their kamiks."

LFPPs also indicated that supportive footwear designed to provide individuals with better grip in winter conditions (e.g., Polar Cleats or detachable rubber soles with toe picks on them) is not necessarily "Elder-friendly" and may increase their likelihood of falling on indoor surfaces. Juanita, an LFPP, explained:

\begin{abstract}
It's hard for them to take off when they come inside. So, a lot of them just wear them all of the time because...it takes a little bit of extra strength to get them on [and off] your feet...They're not really Elder-friendly because a lot of Elders can't bend over, and a lot of Elders don't have the strength to pull those foot guards right over their boots. So, they just leave them on their boot, [which increases their likelihood of slipping on indoor flooring because there is nothing to grip].
\end{abstract}

Like footwear, excessive alcohol consumption can increase the likelihood that an older Inuvialuit adult will fall, according to four participants (one female LFPP, one male Inuvialuit Elder, and two female Inuvialuit Elders). As a local Inuvialuit Elder, Patrick (64 years old), stated, "I don't really like...to say this - but alcohol. It's a big [health and fall-risk] factor on the Elders' [falls]." Moreover, three participants (one male LFPP, and two female LFPPs) felt that personal health practices, such as diet and taking prescribed medications, can also increase the likelihood of older Inuvialuit adults experiencing a fall-related injury or fatality. For example, participants suggested that poor diet could increase an older adult's risk of falling through generalized weakness, fatigue, and frailty resulting from inadequate nutritional intake, and that some medications could increase the chance of falling as a result of druginduced side effects, such as drowsiness, dizziness, and disturbances in gait or vision.

Lastly, four participants (one male LFPP and three female LFPPs) argued that older Inuvialuit adults' personal health practices-more specifically, their personal health behaviours - can also increase their chances of experiencing a fall. The following example, provided by LFPP Jenel, highlights some health behaviours that may increase an older adult's likelihood of experiencing a fall:

They [older Inuvialuit adults] don't want your help [laughs]. And, you know, sometimes you're just letting them go 'cause that is their pride, and that is the only thing that they hold to themselves - that they [can remain] independent...They [feel they] don't need the help or [want to] try out the exercises [that improve muscle strength and endurance] in here [the local rehabilitation centre] [laughs].

Another LFPP, Susan, also provided an example highlighting health behaviours that can increase one's fall risk: 
And you see this - you see that social withdrawal, that social isolation happening a lot-and not just with dementia, [but also] with community-dwelling Elders. And it's a huge issue, social isolation. Because it's a protective coping mechanism, right? It's a way they have of just - it's almost like, "Well, I'm afraid-but it's not that I'm too afraid. It's just that if I don't go to do it [walk outside with a cane or walker, for example], then there's no chance of me falling, or me making a fool of myself, or me looking like an idiot in front of the community" - or all these different things, you know?

Physical Environments: Several participants (one male LFPP, five female LFPPs, four male Inuvialuit Elders, and four female Inuvialuit Elders) cited both outdoor and indoor physical environments as having the potential to increase the likelihood of an older Inuvialuit adult's falling. Most participants agreed that Inuvik's winter conditions (e.g., extremely cold temperatures, relatively consistent snowfall, icy surfaces) substantially increase older Inuvialuit adults' risk of experiencing a fall-related injury or fatality. Jean $(80$ years old), a local Inuvialuit Elder, simply stated, "Honestly, this kind of icy weather-it's very dangerous."

Moreover, both LFPPs and Inuvialuit Elders identified various factors inside private (e.g., one's home) and public (e.g., hospitals, recreation centres) buildings that can also increase an older Inuvialuit adult's fall risk. Some of the most commonly cited fall contributors included overcrowding, trip hazards (e.g., throw rugs, raised bathtubs), ineffective or non-existent assistive living devices (e.g., wobbly rails, unavailable/missing ramps), and building floor plans (e.g., number of stairs, floor material). However, despite the general consensus regarding the concerns about these factors in the indoor physical environment, it is important to highlight that it was generally LFPPs, not Inuvialuit Elders, who identified fallrisk contributors in public settings.

Social Support Networks: Despite the argument by some LFPPs and Inuvialuit Elders that there is a strong sense of community in Inuvik and that people living in the community typically have reliable social support networks, four participants (one male LFPP and three female LFPPs) indicated that the personal perceptions of fall prevention of those in older Inuvialuit adults' support networks might also indirectly increase these older adults' likelihood of falling. For example, Chelsey (LFPP) explained that some older adults' caretakers or families may simply not understand the older adults' need for mobility aids: "Their families won't buy them 'cause they either don't have the money or they don't want to spend their money on that." Additionally, these participants referred to the idea of individuals "over-caring" for their parents or grandparents; specifically, they felt that these individuals took meaningful engagement and physical activity opportunities away from older Inuvialuit adults, which may then increase their likelihood of experiencing a fall-related injury. Crystal M (LFPP) explained:
I think sometimes our Elders get taken care of a lot. So, they're doing less meaningful engagement. So, they're not cooking for themselves, they're not getting their groceries, they're not walking around-they're more housebound...Because there is less meaningful occupation, they can get weakened because they're not walking around. They're not lifting things up. They're not doing things that they had been doing previously because the family's taking care of them.

Access to Health Services: Four participants (four female LFPPs), all of whom were health care providers, felt that older Inuvialuit adults were not always guaranteed access to health services (e.g., ambulation services, health insurance, physiotherapy, or occupational therapy), which could have an impact on their likelihood of falling. As one LFPP participant, Chelsey, explained, access to fall-prevention services, such as home assessments and modifications, are sometimes delayed by local housing corporations or not covered by insurance (e.g., non-insured health benefits). Some LFPPs believed that the housing corporations do not necessarily ensure that needed mobility modifications for older adults' homes are done immediately. Further, Juanita (LFPP) argued that existing services and programs do not provide older Inuvialuit adults with enough opportunities to learn about fall prevention: "I think they [older Inuvialuit adults and their caretakers/family members], a lot of them, lack education on falls, and what prevents falls." (Existing services and programs include long-term care in a facility; home and community care such as respite care, home support, specialist services, and social support; and supported living services that enable Elders to continue living independently.)

\section{SDoIHs That Decrease Likelihood of Falls}

Personal Health Practices and Coping Skills: Whereas LFPPs felt that traditional footwear such as kamiks and mukluks was more likely to increase an older Inuvialuit adult's likelihood of falling, the Inuvialuit Elders who participated in this research, as well as one LFPP, felt that their traditional footwear actually reduces their chances of falling and increases their sense of security, as long as it is properly maintained. Juanita (LFPP) explained:

\footnotetext{
Actually, mukluks are better [than mainstream footwear] if they're not worn really bad. Because mukluks....aren't slippery 'cause the hide is still not at the slippery...shiny [stage]. So, they probably have a better grip in mukluks than they would in normal footwear.
}

Although, as described above, some participants felt that supportive footwear such as Polar Cleats was not "Elderfriendly," two participants (one male LFPP, one female LFPP) indicated that these aids generally decreased the likelihood of an older Inuvialuit adult experiencing fallrelated injuries. Juanita, a LFPP, stated that all the older 
Inuvialuit adults she interacted with used them to avoid slipping during the winter months in Inuvik, and explained, "My Elders [i.e., the Elders with whom she works] all have them [Polar Cleats] on their shoes."

Access to Health Services: Although some participants (four female LFPPs) identified problems with access to health services in Inuvik, three female Inuvialuit Elder participants argued that the existing health services (e.g., disease and injury prevention activities, health care, hospital and home care) generally decreased the likelihood of an older Inuvialuit adult's falling. Local Inuvialuit Elder Jean (80 years old) explained, "If you got good doctors, they help you a lot" with preventing health concerns, like falls. Alice (74 years old), another local Inuvialuit Elder, also felt that older Inuvialuit adults had all the services they needed to take care of their health and well-being, including the programs and interventions needed to prevent a fall: "We [Inuvialuit Elders and older adults] have everything."

\section{SDoIHs Perceived as Having Little Influence on Falls}

Culture: Among the LFPPs and the Inuvialuit Elders, 13 of the 14 participants (five female LFPPs, four male Inuvialuit Elders, and four female Inuvialuit Elders) addressed the relationship - or rather, lack thereofbetween the culture of an Inuvialuit Elder/older adult (or any other Indigenous Elder/older adult) and the likelihood of their experiencing a fall-related injury or fatality. There was resounding agreement among these participants that one's culture had little influence and did not affect the likelihood of an older adult experiencing a fall. Alice (74 years old) explained, "Anybody could fall, so it's-it's not only Inuvialuit - it's all." Jean (80 years old) also agreed, saying, "Anybody can get, you know, [hurt from falling] it's common to anybody." The following statement from Susan, a LFPP, succinctly summarized the participants' opinions that there was no connection between one's culture and the likelihood of a fall:

I mean, something like falls-you're talking about a pretty specific thing, right? I don't see how it changes, and maybe you can tell me how it does. I don't see how it changes cultural or ethnic lines. How is it that an Inuvialuit Elder versus a Gwich'in Elder, versus an Indian elder, versus an African elder-how is there that possibility of them experiencing a fall any different?

Despite the fact these participants all strongly opposed the identification of culture as a fall-risk contributor, one participant (one female LFPP) felt that including cultural activities such as going out on the land, jiggling (fishing), and hunting was a strategy that fall-prevention programmers and health-care professionals can and should use to decrease the likelihood of an older Inuvialuit adult experiencing a fall. Susan explained:
With one of our Elders up here, we're out setting rabbit snares. And one of the reasons why I'm doing thatbesides all the psychosocial benefits of that - one of my goals, or I should say the goal we agreed on, is exercise. When we're doing the snares, it forces her-she's out walking on uneven ground; it challenges her balance; she's got to get down on her hands and knees to do the snare-whatever, you know? But that's using her background to maintain what she has, right?

\section{DISCUSSION}

In this study, LFPPs and Inuvialuit Elders identified the social determinants of Inuit health that they believed increased the likelihood of falls, decreased the likelihood of falls, and had little influence on falls. This research makes an important contribution to better understanding the ways in which fall-prevention initiatives can be tailored to meet older Inuvialuit adults' needs. Below, we discuss the SDoIH identified by the participants and the ways in which these findings support or challenge the existing literature. We also identify steps that can be taken to improve fallprevention programs for older Inuvialuit adults and areas for future research.

\section{SDoIH}

Personal Health Status and Conditions: Knowing that Inuvialuit experience greater challenges with health and access to health care than non-Indigenous peoples is valuable information for LFPPs in Inuvik. By understanding that Inuvialuit have higher rates of poor health, LFPPs can, if needed, provide more or different care for their Inuvialuit patients. LFPPs could provide older Inuvialuit adults with tailored fall-prevention programs that also help manage their chronic conditions and health issues. Older Inuvialuit adults could benefit from programs that included information about the risk factors associated with specific conditions, as well as information about strategies that can help them manage their symptoms and decrease their risk of falling. Including health condition management in older Inuvialuit adults' fall-prevention programs might also help reduce Inuvialuit overall health inequalities. Further research that links data on falls and personal health status in Inuvialuit communities would help to identify the factors that increase the fall risk of older Inuvialuit adults, which would enable researchers and practitioners to strengthen fall-prevention interventions for this population.

Personal Health Practices and Coping Skills: Choice of footwear was given a great deal of attention by the participants in this study; this discussion demonstrated that current footwear guidelines for older adults (i.e., avoiding shoes with soles that are too thick, treads that are too smooth, and heels that are too high or narrow; Tencer et al., 2004; Scott, 2012) were not created with kamiks, mukluks, and northern conditions in mind. Fall prevention 
researchers and practitioners need to adapt the guidelines to an older adult's cultural and geographic context. Shoes that fall-prevention professionals may typically consider as fall hazards, such as kamiks and mukluks, may instead be fall-prevention footwear for this population, if the footwear is well maintained. It is also important for fallprevention researchers and practitioners to be sensitive to the cultural importance of traditional footwear and the fact that Inuvialuit peoples have worn it successfully since time immemorial: advising older Inuvialuit adults to stop using such footwear could be considered an unwelcome colonial intervention.

Alcohol use is another personal health practice and coping skill that participants identified as increasing the likelihood of an older Inuvialuit adult falling. Studies have been conducted on alcohol use and injury among other Arctic populations (see Seale et al., 2006; Healey and Meadows, 2007; Durkalec et al., 2014); however, to date, no studies have addressed alcohol use and abuse among older Inuit adults (Somogyi et al., 2015), or its impact on the likelihood of falling. It is vital that fall-prevention professionals discuss with clients the role alcohol may have in increasing older Inuvialuit adults' chances of falling, but such discussions must be done with great sensitivity, particularly as alcohol abuse has been linked to trauma related to the legacy of residential schools (Ehrlander, 2010; Bombay et al., 2014). Further, existing stigma and discriminatory stereotypes of Indigenous peoples regarding alcoholism (Tang and Browne, 2008) have resulted in maltreatment of Indigenous peoples from health-care service providers. It is therefore important that fall-prevention researchers and practitioners not assume that Indigenous patients and clients have problems with alcohol consumption, but still discuss the issue of alcohol use and fall prevention.

Participants also indicated that diet and prescribed medication increased the likelihood of older Inuvialuit adults experiencing a fall. Certainly, a fall can be due to the fatigue, weakness, frailty, and even acute delirium that can result from dehydration or malnutrition (Vetta et al., 1999; Vivanti et al., 2009), or side effects such as reduced bone mineral density, increased rates of bone loss, increased risk for fracture, postural hypotension, dizziness, or gait disturbance from medications such as anticoagulants, anticonvulsants, antidepressants, antiepileptics, antipsychotics, benzodiazepines, muscle relaxants, and sedative hypnotics (Hartikainen et al., 2007; Moylan and Binder, 2007; Bloch et al., 2010; Cadario and Scott, 2010; Brown and Mezuk, 2012). Indeed, poor diets and prescribed medications can increase the likelihood of an older adult's falling and the possibility of sustaining more serious fallrelated injuries (Vetta et al., 1999; Hartikainen et al., 2007; Moylan and Binder, 2007; Vivanti et al., 2009; Bloch et al., 2010; Cadario and Scott, 2010; Brown and Mezuk, 2010). Thus, older Inuvialuit adults are not exempt from these fallinducing factors, and it is important for LFPPs to be aware of these risks when developing fall-prevention programs for this population.
Access to Health Services: Though there is significant evidence of Indigenous peoples being denied access to an array of health services in Canada (Larson et al., 2011; Senese and Wilson, 2013; Reading and Farber, 2015; Galloway, 2017), the older Inuvialuit adults in this study felt that their likelihood of falling decreased because they were able to use pre-existing services and programs available in Inuvik, such as health care, home care, medevac, physical activity programs (e.g., the older adult fitness classes available through the Beaufort-Delta Health and Social Services), and rehabilitation services (e.g., the home assessments and modifications offered by the Inuvik Regional Hospital's Rehabilitation Department's occupational therapists and the fall-prevention programs offered by the Rehabilitation Department's physiotherapists). While most of the Inuvialuit Elders were quite enthusiastic about the care they received, the LFPPs and several Inuvialuit Elders in this study said that some older Inuvialuit adults may not engage in potentially helpful fall-prevention programs available through health services because of a fear of judgement from community members, fear of losing independence and autonomy, and simple lack of interest in fall-prevention interventions. These findings align with those of other studies, where several factors were found to increase the risk of older adults' falls: engaging in risk-taking behaviours (e.g., clearing snow and ice off a walkway or climbing up a ladder) (Scott, 2012), reducing physical activity (Sherrington and Lord, 1998; Gregg et al., 2000), and not using assistive devices, such as canes and walkers, as a result of negative intra- and interpersonal opinions (Gallagher et al., 2002).

However, the lack of engagement in mainstream health promotion, injury prevention or other health-care services is not a novel finding in health research conducted with Inuit communities and populations in Canada. Past studies (Kirmayer et al., 1994; McDonald and Trenholm, 2010; Cerigo et al., 2013) have actually found that Inuit often engage in anti-help-seeking behaviours as a result of cultural values and beliefs. For example, because it is considered wrong to complain (even if they are experiencing discomfort or pain from a chronic or acute illness), Inuit are significantly less likely to seek any medical assistance than non-Inuit individuals (Quajigiartiit Health Research Centre, 2017). Our findings pertaining to health services access thus warrant investigation to determine whether older Inuvialuit adults' cultural values and beliefs may influence the likelihood of their participation in helpful fallprevention programs.

There are also various ways for LFPPs to assist older Inuvialuit adults in overcoming these barriers. First, LFPPs can attempt to reduce the stigma around falls and fallprevention programs within the community. By teaching the public that falls are preventable and not an inevitable outcome of aging, as well as conveying the idea that everyone can have a role in reducing fall-related injuries in the community, LFPPs can potentially normalize their programs and interventions. The second recommendation 
for LFPPs is to take an empathetic approach while implementing their programs and interventions. LFPPs need to be sensitive to the fact that engaging in a fallprevention program and using fall-prevention interventions, such as mobility aids, is a significant change to an older Inuvialuit adult's life. LFPPs can teach older Inuvialuit adults how to incorporate these programs into their everyday lives and can emphasize how fall-prevention interventions can actually help older Inuvialuit adults to maintain their independence and autonomy.

Physical Environments: The housing conditions of the Inuit and the effect of these conditions on their overall health have been well documented in the literature. Evidence suggests that the Inuit have homes that are typically in need of major repair (i.e., they are made of substandard construction materials), are culturally inappropriate in design (i.e., they do not enable families to incorporate traditional Inuit activities into their everyday lives), and are often overcrowded (Egeland, 2011; Minich et al., 2011). According to Minich et al. (2011), 11.6\% of Inuvialuit from the Inuvialuit Settlement Region live in overcrowded homes, meaning that a significant percentage of the Inuvialuit population experience the negative side effects of overcrowding.

Thus, it is clear why LFPPs and Inuvialuit Elders indicated overcrowding, as well as other related indoor factors (e.g., trip hazards, ineffective or non-existent assistive devices, and ineffective building floor plans) as fall contributors for older Inuvialuit adults. This finding is particularly important because it highlights the fact that older Inuvialuit adults may be in greater need of home assessments and modifications in order to identify and address all the potential fall hazards in their households. LFPPs should thus continue conducting these assessments, as both Inuvialuit Elders and LFPPs agree that they are a useful strategy for reducing older Inuvialuit adults' likelihood of experiencing a fall.

It is also important for LFPPs in Inuvik to develop and implement fall-prevention programs for older Inuvialuit adults' outdoor physical environment, which both LFPPs and the Elder participants identified as particularly challenging because of the prolonged presence of ice and snow. LFPPs need to continue to provide interventions that are adapted to older Inuvialuit adults' physical environment. Moreover, future researchers and practitioners should specifically look for these common outdoor risk factors when conducting environmental fall assessments for older Inuvialuit adults. By identifying these factors, fallprevention professionals can better educate older Inuvialuit adults in Inuvik on effective ways to mitigate these hazards.

Social Support Networks: There are direct links between social factors and fall risk (Chappell and Prince, 1994; Faulkner et al., 2003; Scott et al., 2005; Fabre et al., 2010). Faulkner et al. (2003), for example, conducted a study on social support networks and their effect on elderly Caucasian community-dwelling women's likelihood of falling. Of the $6500+$ women who participated in the study, it was found that women with strong and supportive family relationships were less likely to experience a fall (Faulkner et al., 2003). It is thus evident that social relations (or lack thereof) may directly impact an older adult's likelihood of falls.

Interestingly, the LFPPs' opinions regarding older Inuvialuit adults' social support networks and their impact on the likelihood of falling contradicted Faulkner et al.'s (2003) findings. LFPPs indicated that having a support system could actually increase an older Inuvialuit adult's likelihood of falling. This is because the individuals these older adults include in their network may be unaware of the potentially detrimental impacts their beliefs and behaviours about falls have on older adults. Yet it is not recommended that LFPPs in Inuvik exclude older Inuvialuit adults' support systems from the fall-prevention process; rather, LFPPs should work with them. By including these individuals in older Inuvialuit adults' fall-prevention programs, LFPPs can help them to understand the causes of falling, how to identify and modify fall-risk factors, and what strategies they can use to reduce the likelihood of older adults experiencing a fall. This strategy would also enable LFPPs to reiterate the importance and benefits of fall-prevention programs and interventions to both the older adults and their social support networks. If the family and friends of older adults see these programs and interventions as helpful tools for older Inuvialuit adults to maintain their health and independence, these older adults will probably be more inclined to participate in fall-prevention programs. Therefore, LFPPs should strive to include older Inuvialuit adults' social support networks in the implementation and use of their fall-prevention programs.

Culture: According to Anderson et al. (2003:68), culture is the "integrated patterns of human behavior that include language, thoughts, communication, actions, customs, beliefs, values and institutions of ethnic, religious, or social groups." Culture influences the decisions, interpretations, and meanings significant to individuals' personal lives (Duncan and Ley, 1993). Risk perception, or the subjective judgements that people make about the characteristics and severity of a risk (Rohrmann and Renn, 2000), can therefore also be influenced by one's culture. That is, "perceptions of acceptable risk" (Giles et al., 2015:543) have been found to depend considerably on individuals' cultural backgrounds and worldviews (Masuda and Garvin, 2006; Giles et al., 2010). It is reasonable to assume that culture "plays important roles in injury prevention, as it informs behavioural decisions related to risk taking and healthy lifestyles" (Giles et al., 2015:543). Consequently, fallprevention researchers and practitioners should make an effort to understand the impact culture has on older adults' fall risk and rates.

It was surprising that, despite the explicit suggestions from injury prevention research, the participants in this study outwardly refuted the potential connection between culture and falls. In fact, the majority of the participants fiercely challenged the notion that a relationship between 
the two existed. Further discussion with the LFPPs and Inuvialuit Elders revealed that the Elders may consider that questioning the influence of one's culture on the likelihood of a fall is insulting and even discriminatory. By identifying an individual's culture, as well as other various cultural factors, as a potential fall-risk contributor, fall-prevention professionals could inadvertently re-emphasize existing negative beliefs about Indigenous peoples. By linking culture with injury, researchers and practitioners risk reinforcing a narrative that Inuvialuit culture is injurious. Therefore, because of the sensitive nature of culture and its importance within colonial efforts to eradicate Indigenous peoples, fall-prevention researchers and practitioners working with Inuvialuit Elders need to be careful with the idea of culture being a risk factor for falls. Professionals should refrain from specifically accentuating the idea that culture alone increases fall risk, and instead be cognizant that it may indirectly influence their client's likelihood of falling.

Though participants believed strongly that the entirety of Inuvialuit culture (i.e., language, thoughts, communication, actions, customs, beliefs, values, and institutions) does not influence the likelihood of an Inuvialuit Elder experiencing a fall, various aspects of the culture (e.g., traditional footwear, being supported by family and community) were in fact identified as possible fall-risk factors. But it is important to address how these aspects of Inuvialuit culture can decrease their likelihood of falling as well.

For example, four LFPPs argued that Inuvialuit Elders' social support networks increased their likelihood of experiencing a fall; however, these social systems have been found to improve individuals' health choices and behaviours (Richmond and Ross, 2008). This means that Inuvialuit Elders could potentially draw upon fallprevention knowledge they have received from family members and friends and use it in personal fall-mitigating practices. Further, caring for family (especially Elders) and providing assistance to those in need are important cultural values among the Inuit (Quajigiartiit Health Research Centre, 2017) and can play a significant role in their fall prevention; thus, LFPPs should work with Elders' social support networks in order to reduce their fall risk.

Lastly, one LFPP argued that Inuvialuit cultural activities (e.g., going out on the land, jiggling [fishing], hunting, and setting up snares) could decrease older Inuvialuit adults' likelihood of experiencing a fall. Though jiggling and hunting are not typically included in generic fall-prevention programs, these activities can and should be included in the physical activity component of older Inuvialuit adults' fall-prevention programs. These culturally appropriate activities might help to compensate for the normal agerelated changes older Inuvialuit adults experience, and thus might play a role in reducing their likelihood of falling.

Thus, researchers and practitioners should identify how aspects of Inuvialuit culture can be used to develop fallprevention programs and interventions that are culturally appropriate for older Inuvialuit adults.

\section{CONCLUSION}

Although there is some information pertaining to the influence of the SDH on older Canadian adults' falls, these factors have not been considered from the perspective of older Inuvialuit adults and LFPPs. The interviews conducted with Inuvialuit Elders and LFPPs in Inuvik enabled the identification of the SDoIH that participants believe increase, decrease, and have little influence on the likelihood of older Inuvialuit adults experiencing a fall and fall-related injuries.

These findings provide researchers and practitioners with the information needed to better manage and mitigate older Inuvialuit adults' fall risk. The results of this study challenge current fall-prevention programs and indicate that researchers and practitioners should carefully consider these determinants and their broader implications when developing fall-prevention programs and interventions for Inuvialuit populations, and probably for others, too. Moreover, many factors that contribute to the risk of a fall reveal the vast disparities that continue to negatively impact older Inuvialuit adults: they experience higher rates of physical and mental health issues and live in overcrowded homes; they have limited access to health services, lower incomes, and fewer educational opportunities (NWT Health and Social Services, 2005; ITK, 2008, 2014; Richmond, 2009; Egeland, 2011; Minich et al., 2011; Owens et al., 2012). Discrimination and racism often further exacerbate Inuvialuit peoples' health inequalities, making it that much more difficult for them to seek and receive the care they need. Therefore, researchers and practitioners need to use fall-prevention strategies tailored to the needs of older Inuvialuit adults. However, these professionals must also be cognizant of the fact that injury prevention programs - in this case, fall-prevention programs - may have discriminatory colonial practices embedded within them. This legacy can not only result in older Indigenous adults becoming discouraged from participating in fallprevention programs in the future, but also continue the growth of health disparities experienced by Indigenous peoples in Canada. It is therefore important for these issues to be addressed promptly.

Future studies should consider separately exploring the effect of SDH on fall rates among older adults in First Nations, Métis, Inuit, and other sub-populations in order to elucidate important differences between these populations, and to avoid perpetuating the idea that all older Indigenous adults share the same experiences of fall hazards, injuries, and fatalities. Additional research could also be conducted to compare male and female older Indigenous adults' falls and fall-related injury or fatality rates, as it has been found that older non-Indigenous female adults have a higher risk of falling than their male counterparts. 


\section{REFERENCES}

Anderson, L.M., Scrimshaw, S.C., Fullilove, M.T., Fielding, J.E., and Normand, J. 2003. Culturally competent healthcare systems: A systematic review. American Journal for Preventative Medicine 24(3S):68-79.

https://doi.org/10.1016/S0749-3797(02)00657-8

Ayres, L. 2008. Semi-structured interview. In: Given, L.M., ed. The SAGE encyclopedia of qualitative research methods. Thousand Oaks, California: Sage Publications. 811-813.

Barriball, K.L., and While, A. 1994. Collecting data using a semistructured interview: A discussion paper. Journal of Advanced Nursing 19(2):328-335. https://doi.org/10.1111/j.1365-2648.1994.tb01088.x

Beauvais, A., and Beauvais, J.E. 2014. Reducing the fear of falling through a community evidence-based intervention. Home Healthcare Nurse 32(2):98-105. https://doi.org/10.1097/NHH.0000000000000017

Bjerregaard, P., Young, T.K., Dewailly, E., and Ebbesson, S.O.E. 2004. Indigenous health in the Arctic: An overview of the circumpolar Inuit population. Scandinavian Journal of Public Health 32(5):390-395. https://doi.org/10.1080/14034940410028398

Bloch, F., Thibauld, M., Dugué, B., Brèque, C., Rigaud, A.-S., and Kemoun, G. 2010. Psychotropic drugs and falls in the elderly people: Updated literature review and meta-analysis. Journal of Aging and Health 23(2):329-346.

https://doi.org/10.1177/0898264310381277

Bombay, A., Matheson, K., and Anisman, H. 2014. The intergenerational effects of Indian residential schools: Implications for the concept of historical trauma. Transcultural Psychiatry 51(3):320-338. https://doi.org/10.1177/1363461513503380

Braun, V., and Clarke, V. 2006. Using thematic analysis in psychology. Qualitative Research in Psychology 3(2):77-101. https://doi.org/10.1191/1478088706qp063oa

Brown, M.J., and Mezuk, B. 2012. Brains, bones, and aging: Psychotropic medications and bone health among older adults. Current Osteoporosis Reports 10(4):303-311. https://doi.org/10.1007/s11914-012-0121-4

Cadario, B., and Scott, V. 2010. Drugs and the risk of falling in the elderly: A new guideline from the BC Fall and Injury Prevention Coalition. BC Medical Journal 52(5):268.

Canadian Patient Safety Institute. 2017. Falls. http://www.patientsafetyinstitute.ca/en/Topic/Pages/Falls. aspx

Cerigo, H.C., Coutlée, F., Franco, E.L., and Brassard, P. 2013. Factors associated with cervical cancer screening uptake among Inuit women in Nunavik, Quebec, Canada. BMC Public Health 13(1): 438.

https://doi.org/10.1186/1471-2458-13-438

Chang, V.C., and Do, M.T. 2015. Risk factors for falls among seniors: Implications of gender. American Journal of Epidemiology 181(7):521-531.

https://doi.org/10.1093/aje/kwu268
Chappell, N.L., and Prince, M.J. 1994. Social support among today's seniors (fact sheet). Victoria, British Columbia: University of Victoria Centre on Aging.

Cohen, N., and Arieli, T. 2011. Field research in conflict environments: Methodological challenges and snowball sampling. Journal of Peace Research 48(4):423-435. https://doi.org/10.1177/0022343311405698

Collings, P. 2001. "If you got everything, it's good enough": Perspectives on successful aging in a Canadian Inuit community. Journal of Cross-Cultural Gerontology 16(2):127-155. https://doi.org/10.1023/A:1010698200870

Davidson, A. 2014. Health of Aboriginal peoples. In: Social determinants of health: A comparative approach. Don Mills, Ontario: Oxford University Press. 146-160.

Dewalt, K.M., and Dewalt, B.R. 2002. Participant observation: A guide for fieldworkers. Walnut Creek, California: Altamira Press.

Do, M.T., Chang, V.C., Kuran, N., and Thompson, W. 2015. Fall-related injuries among Canadian seniors, 2005-2013: An analysis of the Canadian Community Health Survey. Health Promotion and Chronic Disease Prevention in Canada 35(7):99-108.

https://doi.org/10.24095/hpcdp.35.7.01

Duncan, J., and Ley, D., eds. 1993. Place/Culture/Representation. London: Routledge.

Durkalec, A., Furgal, C., Skinner, M.W., and Sheldon, T. 2014. Investigating environmental determinants of injury and trauma in the Canadian North. International Journal of Environmental Research and Public Health 11(2):1536-1548.

https://doi.org/10.3390/ijerph110201536

Egeland, G.M. 2011. IPY Inuit Health Survey speaks to need to address inadequate housing, food insecurity and nutrition transition. International Journal of Circumpolar Health 70(5):444-446.

https://doi.org/10.3402/ijch.v70i5.17854

Ehrlander, M. 2010. The historical roots of a frontier alcohol culture: Alaska and northern Canada. Northern Review 32:63-103.

Erber, E., Beck, L., De Roose, E., and Sharma, S. 2010. Prevalence and risk factors for self-reported chronic disease amongst Inuvialuit populations. Journal of Human Nutrition and Dietetics 23(s1):43-50. https://doi.org/10.1111/j.1365-277X.2010.01092.x

Fabre, J.M., Ellis, R., Kosma, M., and Wood, R.H. 2010. Falls risk factors and a compendium of falls risk screening instruments. Journal of Geriatric Physical Therapy 33(4):184-197.

Faulkner, K.A., Cauley, J.A., Zmuda, J.M., Griffin, J.M., and Nevitt, M.C. 2003. Is social integration associated with the risk of falling in older community-dwelling women? The Journal of Gerontology: Series A, Biological Sciences and Medical Sciences 58(10):M954-M959. https://doi.org/10.1093/gerona/58.10.M954

Fontana, A., and Frey, J.H. 2005. The interview: From neutral stance to political involvement. In: Denzin, N.K., and Lincoln, Y.S., eds. The SAGE handbook of qualitative research, 3rd ed. Thousand Oaks, California: Sage Publications. 695-728. 
Gallagher, E.M., Scott, V., Thomas, P., and Hughes, L. 2002. Final report: Laying the groundwork for improved knowledge and use of assistive devices among Canadian veterans and seniors. Final report for Health Canada. Victoria, British Columbia: School of Nursing, University of Victoria.

Galloway, G. 2017. Ottawa still failing to provide adequate health care on reserves: Report. The Globe and Mail, January 25. https://beta.theglobeandmail.com/news/politics/ottawa-stillfailing-to-provide-adequate-health-care-on-reserves-report/ article33746065/?ref=http://www.theglobeandmail.com\&

Giles, A.R., and Castleden, H. 2008. Community co-authorship in academic publishing: A commentary. Canadian Journal of Native Education 31(1):208-213.

Giles, A.R., Castelden, H., and Baker, A.C. 2010. "We listen to our Elders. You live longer that way": Examining aquatic risk communication and water safety practices in Canada's North. Health \& Place 16(1):1-9.

https://doi.org/10.1016/j.healthplace.2009.05.007

Giles, A.R., Hognestad, S., and Brooks, L.A. 2015. The need for cultural safety in injury prevention. Public Health Nursing 32(5):543-549.

https://doi.org/10.1111/phn.12210

Gillespie, L.D., Robertson, M.C., Gillespie, W.J., Sherrington, C., Gates, S., Clemson, L.M., and Lamb, S.E. 2012. Interventions for preventing falls in older people living in the community. Cochrane Database of Systematic Reviews 1(9): CD007146. https://doi.org/10.1002/14651858.CD007146.pub3

Gregg, E.W., Pereira, M.A., and Caspersen, C.J. 2000. Physical activity, falls, and fractures among older adults: A review of the epidemiologic evidence. Journal of the American Geriatrics Society 48(8):883-893.

https://doi.org/10.1111/j.1532-5415.2000.tb06884.x

Hartikainen, S., Lönnroos, E., and Louhivouri, K. 2007. Medication as a risk factor for falls: Critical systematic review. The Journals of Gerontology: Series A 62(10):1172-1181. https://doi.org/10.1093/gerona/62.10.1172

Healey, G.K., and Meadows, L.M. 2007. Inuit women's health in Nunavut, Canada: A review of the literature. International Journal of Circumpolar Health 66(3):199-214. https://doi.org/10.3402/ijch.v66i3.18256

Health Canada. 2002. A statistical profile on the health of First Nations in Canada: Vital statistics for Atlantic and Western Canada, 2001/2002.

https://www.canada.ca/en/health-canada/services/ first-nations-inuit-health/reports-publications/ aboriginal-health-research/statistical-profile-health-firstnations-canada-vital-statistics-atlantic-western-canada-20012002-health-canada-2011.html

- 2012. Diseases that affect First Nations and Inuit communities.

http://www.hc-sc.gc.ca/fniah-spnia/diseases-maladies/indexeng.php

Herman, M., Gallagher, E., and Scott, V. 2006. The evolution of seniors' falls prevention in British Columbia. Victoria: British Columbia Ministry of Health.

http://www.health.gov.bc.ca/library/publications/year/2006/ falls_report.pdf
Hill, A.D., Pinto, R., Nathens, A.B., and Fowler, R.A. 2014. Agerelated trends in severe injury hospitalization in Canada. Journal of Trauma and Acute Care Surgery 77(4):608-613. https://doi.org/10.1097/TA.0000000000000412

Hopping, B.N., Erber, E., Beck, L., De Roose, E., and Sharma, S. 2010. Inuvialuit adults in the Canadian Arctic have a high body mass index and self-reported physical activity. Journal of Human Nutrition and Dietetics 23(s1):115-119. https://doi.org/10.1111/j.1365-277X.2010.01103.x

Ioannidis, G., Papaioannou, A., Hopman, W.M., Akhtar-Danesh, N., Anastassiades, T., Pickard, L., Kennedy, C.C., et al. 2009. Relation between fractures and mortality: Results from Canadian Multicentre Osteoporosis Study. Canadian Medical Association Journal 181(5):265-271.

https://doi.org/10.1503/cmaj.081720

ITK (Inuit Tapiriit Kanatami). 2008. Inuit in Canada: A statistical profile.

https://www.itk.ca/wp-content/uploads/2016/07/Inuit StatisticalProfile2008_0.pdf

- 2014. Social determinants of Inuit health in Canada. https://itk.ca/wp-content/uploads/2016/07/ITK_Social_ Determinants_Report.pdf

Jin, A., Lalonde, C.E., Brussoni, M., McCormick, R., and George, M.A. 2015. Injury hospitalizations due to unintentional falls among the Aboriginal population of British Columbia, Canada: Incidence, changes over time, and ecological analysis of risk markers, 1991 -2010. PLoS ONE 10(3): e0121694.

https://doi.org/10.1371/journal.pone.0121694

Kirmayer, L.J., Fletcher, C., Corin, E., and Boothroyd, L. 1994. Inuit concepts of mental health and illness: An ethnographic study. Montréal, Quebec: Sir Mortimer B. Davis-Jewish General Hospital, Culture \& Mental Health Research Unit.

Larson, B., Herx, L., Williamson, T., and Crowshoe, L. 2011. Beyond the barriers: Family medicine residents' attitudes towards providing Aboriginal health care. Medical Education 45(4):400-406. https://doi.org/10.1111/j.1365-2923.2010.03892.x

Maguire, P. 1987. Doing participatory research: A feminist approach. Amherst, Massachusetts: The Center for International Education.

Markle-Reid, M.F., Dykeman, C.S., Reimer, H.D., Boratto, L.J., Goodall, C.E., and McGugan, J.L. 2015. Engaging community organizations in falls prevention for older adults: Moving from research to action. Canadian Journal of Public Health 106(4):189-196. https://doi.org/10.17269/cjph.106.4776

Marshall, M.N. 1996. Sampling for qualitative research. Family Practice 13(6):522-525.

https://doi.org/10.1093/fampra/13.6.522

Masuda, J.R., and Garvin, T. 2006. Place, culture, and the social amplification of risk. Risk Analysis 26(2):437-454. https://doi.org/10.1111/j.1539-6924.2006.00749.x

McDonald, J.T., and Trenholm, R. 2010. Cancer-related health behaviours and health service use among Inuit and other residents in Canada's North. Social Science \& Medicine, 70(9):1396-1403. https://doi.org/10.1016/j.socscimed.2010.01.008 
Minich, K., Saudny, H., Lennie, C., Wood, M., WilliamsonBathory, L., Cao, Z., and Egeland, G.M. 2011. Inuit housing and homelessness: Results from the International Polar Year Inuit Health Survey, 2007-2008. International Journal of Circumpolar Health 70(5):520-531.

Moylan, K.C., and Binder, E.F. 2007. Falls in older adults: Risk assessment, management and prevention. The American Journal of Medicine 120(6):493-497.

https://doi.org/10.1016/j.amjmed.2006.07.022

Naraynsingh, R., Sammy, I., Paul, J.F., and Nunes, P. 2015. Trauma in the elderly in Trinidad and Tobago: A cross-sectional study. European Journal of Emergency Medicine 22(3):219-221. https://doi.org/10.1097/MEJ.0000000000000196

NWT Bureau of Statistics. 2016a. Inuvik. http://statsnwt.ca/community-data/infrastructure/Inuvik.html

_. 2016b. Inuvik - statistical profile.

http://www.statsnwt.ca/community-data/Profile-PDF/Inuvik. pdf

NWT Health and Social Services. 2005. The NWT Health Status Report 2005.

http://pubs.aina.ucalgary.ca/health/60751E.pdf

- 2015. Injury in the Northwest Territories, 2000-2009.

https://www.hss.gov.nt.ca/sites/hss/files/injury-nwt-2000 -2009.pdf

Owens, S., De Wals, P., Egeland, G., Furgal, C., Mao, Y., Minuk, G.Y., Peters, P.A., Simard, M., and Dewailly, E. 2012. Public health in the Canadian Arctic: Contributions from International Polar Year research. Climatic Change 115(1):259-281.

https://doi.org/10.1007/s10584-012-0569-3

Parachute. 2015. Fall prevention. http://www.parachutecanada.org/injury-topics/topic/C20

Peel, N.M., Kassulke, D.J., and McClure, R.J. 2002. Population based study of hospitalised fall related injuries in older people. Injury Prevention 8(4):280-283.

https://doi.org/10.1136/ip.8.4.280

PHAC (Public Health Agency of Canada). 2011. Social determinants of health and health inequalities. Ottawa: PHAC. http://www.phac-aspc.gc.ca/ph-sp/determinants/index-eng. php\#determinants

— 2014. Seniors' falls in Canada: Second report.

http://www.phac-aspc.gc.ca/seniors-aines/publications/public/ injury-blessure/seniors_falls-chutes_aines/assets/pdf/seniors falls-chutes_aines-eng.pdf

Quajigiartiit Health Research Centre. 2017. Health care expectations: "A note to my clinician." Health NU Mobile application software. Iqaluit: Department of Health, Government of Nunavut.

Reading, J., and Farber, B. 2015. Why is Canada ignoring the health of Aboriginal peoples? The Globe and Mail, April 9. https://beta.theglobeandmail.com/globe-debate/whyis-canada-ignoring-the-health-of-aboriginal-peoples/ article23856403/
Reading, J., Scott, V., Perron, D., Edgar, R., Baba, L., Elliot, S., and Yassin, Y., eds. 2011. Introduction. In: Healthy aging through fall prevention among older Aboriginal people - From many voices to a shared vision. $3-4$.

https://www.uvic.ca/research/centres/circle/assets/docs/ Publications/healthyaging-cahr.pdf

Richmond, C.A.M. 2009. The social determinants of Inuit health: A focus on social support in the Canadian Arctic. International Journal of Circumpolar Health 68(5):471-487.

https://doi.org/10.3402/ijch.v68i5.17383

Richmond, C.A.M., and Ross, N.A. 2008. Social support, material circumstance and health behaviour: Influences on health in First Nation and Inuit communities of Canada. Social Science \& Medicine 67(9):1423-1433.

https://doi.org/10.1016/j.socscimed.2008.06.028

Rohrmann, B., and Renn, O. 2000. Risk perception research: An introduction. In: Renn, O., and Rohrmann, B., eds. Crosscultural risk perception: A survey of empirical studies. Dordrecht: Kluwer Academic Publishers. 13-43.

Scott, V. 2012. Fall prevention programming: Designing, implementing and evaluating fall prevention programs for older adults. Raleigh, North Carolina: Lulu Publishing.

Scott, V., Pearce, M., and Pengelly, C. 2005. Technical report: Injury resulting from falls among Canadians age 65 and over on the analysis of data from the Canadian Community Health Survey, Cycle 2.1.

http://www.phac-aspc.gc.ca/seniors-aines/alt-formats/pdf/ publications/pro/injury-blessure/seniors_falls/technicalreport-injury_e.pdf

Scott, V., Wagar, L., and Elliott, S. 2010. Falls \& related injuries among older Canadians: Fall-related hospitalizations \& prevention initiatives. Prepared on behalf of the Public Health Agency of Canada, Division of Aging and Seniors. Victoria, British Columbia, Canada: Victoria Scott Consulting.

http://www.hiphealth.ca/media/research_cemfia_phac_epi_ and_inventor_20100610.pdf

Seale, J.P., Shellenberger, S., and Spence, J. 2006. Alcohol problems in Alaska Natives: Lessons from the Inuit. American Indian and Alaska Native Mental Health Research 13(1):1-31. https://doi.org/10.5820/aian.1301.2006.1

Senese, L.C., and Wilson, K. 2013. Aboriginal urbanization and rights in Canada: Examining implications for health. Social Science \& Medicine 91:219-228.

https://doi.org/10.1016/j.socscimed.2013.02.016

Sherrington, C., and Lord, S.R. 1998. Increased prevalence of fall risk factors in older people following hip fracture. Gerontology 44(6):340-344.

https://doi.org/10.1159/000022039

Somogyi, B.K., Barker, M., MacLean, C., and Grischkan, P. 2015. Inuit elderly: A systematic review of peer reviewed journal articles. Journal of Gerontological Social Work 58(5):484-502. https://doi.org/10.1080/01634372.2015.1032469 
Statistics Canada. 2007. Aboriginal population profile, 2006 census: Inuvik, Northwest Territories.

http://www12.statcan.ca/census-recensement/2006/dp-pd/ prof/92-594/details/page.cfm?Lang $=\mathrm{E} \& \mathrm{Geol}=\mathrm{CSD} \&$ Code $1=6$ $107017 \&$ Geo $2=$ PR \&Code $2=61 \&$ Data $=$ Count $\&$ SearchText $=$ In uvik $\&$ SearchType $=$ Begins $\&$ SearchPR $=01 \& B 1=$ All $\&$ GeoLeve $1=$ PR\&GeoCode $=6107017$

- 2015. Projected life expectancy at birth by sex, by Aboriginal identity.

http://www.statcan.gc.ca/pub/89-645-x/2010001/c-g/c-g013eng.htm

Stevens, J.A., and Sogolow, E.D. 2005. Gender differences for non-fatal unintentional fall related injuries among older adults. Injury Prevention 11(2):115-119. https://doi.org/10.1136/ip.2004.005835

Stewart-Williams, J., Kowal, P., Hestekin, H., O’Driscoll, T., Peltzer, K., Yawson, A., Biritwum, R., et al. 2015. Prevalence, risk factors and disability associated with fall-related injury in older adults in low- and middle-income countries: Results from the WHO Study on global AGEing and adult health (SAGE). BMC Medicine 13(1): 147. https://doi.org/10.1186/s12916-015-0390-8

Tang, S.Y., and Browne, A.J. 2008. 'Race' matters: Racialization and egalitarian discourses involving Aboriginal people in the Canadian health care context. Ethnicity \& Health 13(2):109-127. https://doi.org/10.1080/13557850701830307

Tencer, A.F., Koepsell, T.D., Wolf, M.E., Frankenfeld, C.L., Buchner, D.M., Kukull, W.A., LaCroix, A.Z., Larson, E.B., and Tautvydas, M. 2004. Biomechanical properties of shoes and risk of falls in older adults. Journal of the American Geriatrics Society 52(11):1840-1846. https://doi.org/10.1111/j.1532-5415.2004.52507.x
Vetta, F., Ronzoni, S., Taglieri, G., and Bollea, M.R. 1999. The impact of malnutrition on the quality of life in the elderly. Clinical Nutrition 18(5):259-267. https://doi.org/10.1016/S0261-5614(98)80022-8

Vivanti, A.P., McDonald, C.K., Palmer, M.A., and Sinnot, M. 2009. Malnutrition associated with increased risk of frail mechanical falls among older people presenting to an emergency department. Emergency Medicine Australasia 21(5):386-394. https://doi.org/10.1111/j.1742-6723.2009.01223.x

Wallerstein, N., and Duran, B. 2010. Community-based participatory research contributions to intervention research: The intersection of science and practice to improve health equity. American Journal of Public Health 100(S1):S40-S46. https://doi.org/10.2105/AJPH.2009.184036

Wilson, K., Rosenberg, M.W., Abonyi, S., and Lovelace, R. 2010. Aging and health: An examination of differences between older Aboriginal and non-Aboriginal people. Canadian Journal of Aging 29(3):369-382. https://doi.org/10.1017/S0714980810000309

WHO (World Health Organization). 2016. Global Health Observatory (GHO) data: Life expectancy. http://www.who.int/gho/mortality_burden_disease/life_ tables/situation_trends/en/ 2017. About social determinants of health. http://www.who.int/social_determinants/sdh_definition/en/ . 2018. Falls. http://www.who.int/news-room/fact-sheets/detail/falls

Yin, R.K. 1994. Case study research: Design and methods, 2nd ed. Thousand Oaks, California: Sage Publications. 